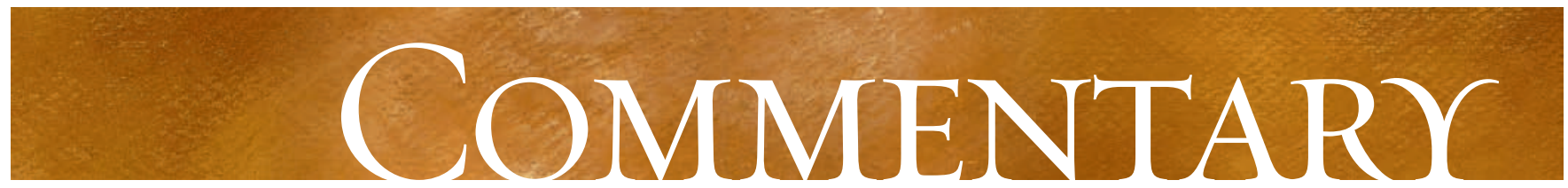

\title{
"You can't always get what you want" - Or can you?
}

\author{
Joan M. Teno, David Dosa
}

$\infty \quad$ See related article page 627

You can't always get what you want

But if you try sometimes

You just might find

You just might find

You get what you need

- Mick Jagger / Keith Richards, Let it Bleed, 1969

I $\mathrm{n}$ the dawn of this new millennium, industrialized nations are struggling with how best to provide health care to older people dying of chronic progressive illnesses. For the most part, health care systems in the industrialized world were built to care for people with acute illness. This fact has resulted in the development of health care silos that are inherently disconnected from one another and thus necessitate frequent transitions from one part of the system to another. ${ }^{1}$ These transitions may result in the neglect of certain needs, failed communication, and overall dissatisfaction with the quality of care. ${ }^{2}$ Given the aging of the populations of industrialized nations, a key challenge is to reform health care systems to allow them to meet the needs and expectations of older people and those who care for them.

A vital first step in this transformation is to understand what dying people want. In this issue (page 627), Heyland and colleagues ${ }^{3}$ provide important evidence about what matters most to dying people and to families living each day with chronic, progressive illnesses that will result in death. The trajectory of dying has changed dramatically in comparison with Ioo years ago, when most deaths were caused by infectious disease and the process of dying could be measured in mere days or weeks after the initial diagnosis. Today, most people in the developed world die at an older age with multiple chronic illnesses whose course is characterized by periods of improvement followed by deterioration and prolonged periods of functional dependency. ${ }^{4}$

What do seriously ill people with life-limiting illnesses want? Items identified by Heyland and colleagues ${ }^{3}$ as "extremely important" include trust in one's physicians, avoidance of a prolonged dying experience on life support, a sense of closure, not being a burden on one's family, adequate supportive services for care at home, symptom relief and open communication. This list is consistent with survey development work that has relied on focus groups, structured interviews, guidelines and expert opinion..$^{5-8}$ Heyland and col-

leagues provide important information on what people want, the key challenge being to ensure that the health care system can respond to these expectations and needs. And so, where do we go from here?

First, measuring patient and family perceptions of the quality of care will play a key role in raising awareness and monitoring changes in how the provision of health care is structured for an aging population. This will in turn help us to focus efforts on improving care and setting standards against which health care systems and institutions can be held accountable. Although measurement has focused on examining the quality of care in "the dying process," it is important that we move from a focus on the quality of end-of-life care to a focus on patient- and family-centred care. Simply stated, we need measures to ensure that we meet the expectations and needs of patients throughout the course of their disease. In developing a conceptual model to examine the quality of care delivered to hospice patients, we have noted that many of the measures do not apply only to the very last stages of life; good pain control, for example, should apply throughout the course of a terminal illness.

Second, palliative care specialists and other physicians who deal with elderly and chronically ill patients must become involved and be leaders in health information technology. Palliative care physicians can have the greatest impact on quality of care by working with the designers of electronic medical records (EMR) and guideline-based computer decision support programs to ensure that appropriate measures and content from their specialty are incorporated. Most guidelines exist as simplistic, branching flow diagrams, yet we make medical decisions that involve far more complexity. With the full implementation of EMR and the use of computer decision-support programs, current guidelines must quickly make the leap from the "generic" patient (e.g., the patient with cancer who rates his or her pain level at 6 on a ropoint scale) to provide patient-specific treatment recommendations that take into account comorbidities, multiple etiologies of pain and the changing pharmacodynamics of aging patients (e.g., a Ioo-year-old patient with breast cancer, bony metastases and 3 different pain syndromes). Guidelinebased computer decision-support systems can effectively provide health care providers with authoritative recommendations that take such complexity into account. Additionally, computer decision-support systems can provide timely feed- 
back that will help avoid common pitfalls in the use of opiates (e.g., the use of long-acting opiates in frail, older, opiatenaive patients as first-line therapy). It is also to be hoped that EMR and computerized decision-support systems can help coordinate care across multiple settings and provide timely information on the quality of care. In this latter role, they can serve as the "bricks and mortar" that sustain the gains of rapid-cycle quality improvement efforts.

Third, we need to invest in organizational culture change. It is somewhat disconcerting that the top-ranked desire reported in Heyland and colleagues' study was "To have trust and confidence in the doctors looking after you." We can only hope this does not reflect a present lack of confidence in health care providers. Acute care hospitals must embrace a culture of patient centredness. This kind of transformation requires us to move beyond a quality-assurance model (e.g., sending physicians assessment letters advising them that they need to be better communicators in the face of slipping satisfaction scores) to complex, multifaceted interventions that align the culture of acute care hospitals with their key mission of providing competent, compassionate and coordinated health care. For example, Brown Medical School in Providence, RI, collaborated with Quality Partners of Rhode Island, a nonprofit consultancy, to use a multifaceted intervention that resulted in a $4 \mathrm{I} \%$ reduction in the rate of severe pain among nursing home residents. ${ }^{9}$

Industrialized nations must now face the need to care for burgeoning populations of older people. Research by the Canadian Researchers at the End of Life Network (CARENET) provides important evidence about what Canadians with lifethreatening illnesses want. Now is an important time for physicians and other health care providers, policy-makers, health service researchers and administrators to work to- gether to ensure that this generation get what they need in their final stages of life.

Joan Teno is with the Center for Gerontology and Health Care Research, Brown University and Brown Medical School, Providence, RI. David Dosa is with the Division of Geriatric Medicine, Rhode Island Hospital, Providence, RI.

Competing interests: None declared.

Contributors: Both authors contributed equally to the preparation of this article.

\section{REFERENCES}

I. Coleman EA, Min SJ, Chomiak A, et al. Posthospital care transitions: patterns, complications, and risk identification. Health Serv Res 2004;39:I449-65.

2. Teno JM, Clarridge BR, Casey V, et al. Family perspectives on end-of-life care at the last place of care. JAMA 2004;291:88-93.

3. Heyland DK, Dodek P, Rocker G, et al. What matters most in end-of-life care: perceptions of seriously ill patients and their family members. $C M A J$ 2006;174(5): 627-33.

4. Teno JM, Weitzen S, Fennell ML, et al. Dying trajectory in the last year of life: Does cancer trajectory fit other diseases? J Palliat Med 2001;4:457-64.

5. Teno JM, Clarridge B, Casey V, et al. Validation of Toolkit After-Death Bereaved Family Member Interview. J Pain Symptom Manage 200I;22:752-8.

6. Steinhauser KE, Christakis NA, Clipp EC, et al. Factors considered important at the end of life by patients, family, physicians, and other care providers. JAMA 2000;284:2476-82.

7. Steinhauser KE, Clipp EC, McNeilly M, et al. In search of a good death: observations of patients, families, and providers. Ann Intern Med 2000; I32(I0)825-32.

8. Curtis JR, Patrick DL, Engelberg RA, et al. A measure of the quality of dying and death. Initial validation using after-death interviews with family members. J Pain Symptom Manage 2002;24:17-31.

9. Baier RR, Gifford DR, Patry G, et al. Ameliorating pain in nursing homes: a collaborative quality-improvement project. J Am Geriatr Soc 2004;52:1988-95.

Correspondence to: Dr. Joan Teno, Department of Community Health, Brown Medical School, 2 Stimson Ave., Providence RI o2806; fax 40I 863-I742; Joan_Teno@brown.edu 